Ann. Zootech., I977, 26 (3), 297-313.

I.N.R.A.

BIBLIOTHEQUE UO 35906

DOMAINE DE CROUELLE

63039

CLERMONT-FD CEDEX?

\title{
Allaitement artificiel de l'aǵneau \\ VI. - Comparaison de différentes teneurs en matières azotées du lait de remplacement
}

\author{
M. THERIEZ, P. PATUREAU-MIRAND * et G. MOLENAT \\ avec la collaboration de \\ A. Brelurut, J.-P. Brun et P. Dacheux \\ Station de Recherches sur l'Elevage des Ruminants, \\ * Labovatoive du Métabolisme azoté, \\ Centre de Recherches de Clemont-Ferrand, I.N.R.A., \\ Theix - St-Genès-Champanelle \\ 63 IIO Beaumont (France)
}

\section{Résumé}

Au cours de deux essais successifs, nous avons offert pendant 6 semaines à too agneaux nouveau-nés 4 aliments d'allaitement contenant 20,25 ou $30 \mathrm{p} .100$ de matières azotées ou $29 \mathrm{p}$. ı oo de matières azotées et une supplémentation en acides aminés industriels.

Nous avons également mesuré le coefficient de digestibilité de ces aliments ainsi que la quantité d'azote fixée par jour. Après le sevrage les agneaux ont été engraissés avec un même régime de foin et d'aliment concentré.

L'augmentation de la teneur en matières azotées ou la supplémentation en acides aminés améliore la digestibilité des matières azotées des aliments et la quantité d'azote fixée par jour. Elle n'a pas d'effet sur la, vitesse de croissance des agneaux (ni avant, ni après le sevrage), ni sur l'état d'engraissement de leur carcasse.

\section{Introduction}

Différents auteurs (Walker et Faichney, i964; Norton et Walker, I97I; Chiou et Jordan, I973 a, b; Black, Pearce et Tribe, I973) ont étudié chez l'agneau l'effet de la teneur en matières azotées des aliments d'allaitement sur leur digestibilité, la rétention azotée ainsi que sur la vitesse de croissance de l'animal (ces derniers résultats sont reportés sur le tabl. r). Lorsque la teneur en matières azotées des laits de remplacement augmente, passant de 6 à 30 p. Ioo de la matière sèche, leur digestibilité s'élève ct le gain de poids vif quotidien est amélioré. Cependant, au delà de 30 p. Ioo de matières azotées, la croissance des agneaux diminue (Black, Pearce et Tribe, r973; Chiou et Jordan, I973 a, b).

L'équilibre en acides aminés des aliments d'allaitement a par contre été peu étudié (WALKER, I975; WALKER et KIRK, I975), or les agneaux se comportent 
avant le sevrage comme des monogastriques et doivent trouver dans leur régime les acides aminés indispensables en quantité suffisante. En outre, la majeure partie des expériences ont été conduites avec des animaux qui recevaient des quantités de matière sèche limitées et qui avaient, sauf exception (BLACK, PEARCE et Tribe, I973) des gains de poids vif inférieurs à $200 \mathrm{~g} / \mathrm{j}$. Il est donc difficile de généraliser les résultats disponibles au cas des agneaux qui doivent réaliser des vitesses de croissance voisines de $300 \mathrm{~g} / \mathrm{j}$. C'est pourquoi nous avons étudié l'influence de la teneur en matières azotées ( 20 à $30 \mathrm{p}$. I 00 de la matière sèche) de l'aliment d'allaitement ainsi que celle d'une supplémentation en acides aminés, reproduisant un équilibre en acides aminés voisin de celui du lait de brebis, sur les performances d'agneaux à croissance rapide.

\section{TABLEAU I}

Résumé des données bibliographiques sur l'influence de la teneur en matières azotées du lait de remplacement sur la vitesse de croissance de l'agneau

Summary of published main results on the effect of protein content of milk replacers on the lamb's growth vate

\begin{tabular}{|c|c|c|c|c|c|}
\hline \multirow{2}{*}{ Auteurs } & \multirow{2}{*}{ Mode d'alimentation } & \multicolumn{2}{|c|}{$\begin{array}{c}\text { Teneur de l'aliment } \\
\text { d'allaitement (p. roo) } \\
\text { en }\end{array}$} & \multirow{2}{*}{$\begin{array}{l}\text { Pourcentage } \\
\text { de l'énergie } \\
\text { apportéc } \\
\text { sous forme de } \\
\text { protéines }\end{array}$} & \multirow{2}{*}{$\begin{array}{l}\text { Gain } \\
\text { quotidier } \\
(\mathrm{g} / \mathrm{j})\end{array}$} \\
\hline & & $\begin{array}{l}\text { matières } \\
\text { azotées }\end{array}$ & $\begin{array}{l}\text { matières } \\
\text { grasses }\end{array}$ & & \\
\hline $\begin{array}{c}\text { WaLkER et } \\
\text { FAICHNEY (I.964) }\end{array}$ & $\begin{array}{l}3 \text { repas en quantité limitée } \\
3 \text { meals restricted quantity }\end{array}$ & $\begin{array}{l}I 7,6 \\
23, \mathrm{I} \\
28,5 \\
32,8\end{array}$ & $\begin{array}{l}17,1 \\
22,3 \\
27,6 \\
25,8\end{array}$ & $\begin{array}{l}20,2 \\
24,8 \\
28,7 \\
33,0\end{array}$ & $\begin{array}{r}77 \\
109 \\
131 \\
149\end{array}$ \\
\hline $\begin{array}{c}\text { Norton et } \\
\text { WAL KER (I97I) }\end{array}$ & $\begin{array}{l}2 \text { repas en quantité limitée } \\
2 \text { meals restricted quantity }\end{array}$ & $\begin{array}{r}6,1 \\
28,5\end{array}$ & $\begin{array}{l}56,6 \\
27,6\end{array}$ & $\begin{array}{r}5,0 \\
28,7\end{array}$ & $\begin{array}{r}2 \\
125\end{array}$ \\
\hline $\begin{array}{c}\text { ChIOU et } \\
\text { JoRdan } \\
(\text { I } 973 \text { a et b) }\end{array}$ & $\begin{array}{c}\text { A volonté avec un } \\
\text { maximum de } 3 \text { oo } \mathrm{g} \\
\text { de MS/animal /jour } \\
\text { Ad libitum with } 3 \text { oo } g \text { of } \\
\text { DM/lamb/day as a } \\
\text { maximum }\end{array}$ & $\begin{array}{l}\text { (a) } 33, \mathrm{I} \\
3 \mathrm{I}, 8 \\
32,8 \\
\text { (b) } 15 \\
15 \\
23 \\
23 \\
30 \\
30\end{array}$ & $\begin{array}{l}\text { I3 } \\
22 \\
29,6 \\
15 \\
30 \\
\text { I } 5 \\
30 \\
\text { I } 5 \\
30\end{array}$ & $\begin{array}{l}38,7 \\
33,5 \\
32,5 \\
17,4 \\
14,8 \\
25,4 \\
21,6 \\
34,7 \\
31,3\end{array}$ & $\begin{array}{l}178 \\
206 \\
196 \\
112 \\
116 \\
145 \\
152 \\
220 \\
183\end{array}$ \\
\hline $\begin{array}{l}\text { Black, Pearce } \\
\text { et Tribe } \\
\text { (I } 973)\end{array}$ & $\begin{array}{l}\text { Limité } \\
\text { Restricted }\end{array}$ & $\begin{array}{l}\text { I } 5 \\
25 \\
35 \\
4^{\circ}\end{array}$ & $\begin{array}{l}27 \\
24 \\
21 \\
19\end{array}$ & $\begin{array}{l}\text { I } 5 \\
25 \\
35 \\
40\end{array}$ & $\begin{array}{l}201 \\
319 \\
308 \\
23^{8}\end{array}$ \\
\hline 4uthors & Feeding method & Protein & $\begin{array}{l}\text { at of } \\
\text { placer }\end{array}$ & $\begin{array}{l}\text { Percentage of } \\
\text { total energy } \\
\text { supplied } \\
\text { as protein }\end{array}$ & $\begin{array}{l}\text { Daily } \\
\text { weight } \\
\text { gain } \\
(s / d)\end{array}$ \\
\hline
\end{tabular}




\section{Matériel et méthodes}

Au cours de deux essais successifs nous avons offert à des agneaux, à partir de l'âge de 3 jours et jusqu'au sevrage à 42 jours, des aliments d'allaitement contenant 20,25 ou 30 p. 100 de matières azotées $\left({ }^{1}\right)$. Nous avons également utilisé, lors du premier essai seulement, un aliment contenant 29 p. Ioo de matières azotées et enrichi en DL-méthionine. L-isoleucine, L-lysine et L-arginine. La composition de cet aliment et la supplémentation en particulier ont été déterminées par comparaison entre le lait de brebis, considéré comme l'aliment de référence pour l'agneau, et le lait de vache, source classique de matières azotées des laits de remplacement. Dans cet aliment la somme corrigée des acides aminés indispensables et leur équilibre sont sensiblement les mêmes que ceux du lait de brebis.

Lors du premier essai, les aliments ont été distribués selon deux niveaux d'apport (à volonté ou en quantité limitée) à des agneaux logés en cases individuelles pendant la phase lactée. Au cours du deuxième essai nous n'avons utilisé que 3 aliments (20-25 et 30$)$ et nous les avons offert à volonté à des agneaux élevés en lots.

Après le sevrage, tous les agneaux ont été alimentés en lots, ceux du $2^{\mathrm{e}}$ essai sont restés dans leurs lots initiaux et ceux du I ${ }^{\text {er }}$ essai ont été regroupés en fonction de leurs traitements initiaux. Ils ont alors reçu des régimes à base de foin et d'aliment concentré jusqu'à l'abattage. Par ailleurs, les teneurs en urée et acides aminés libres du sang ont été déterminées à 8 jours (essai I) et à 2I jours (essais I et 2). Les résultats relatifs à ces mesures sont présentés par ailleurs (PATUREAUMiRAND et al., I977).

\section{Aliments et mode de distribution}

\section{Phase lactée}

Les aliments expérimentaux ayant fait l'objet de deux fabrications (une par essai), il existe de légères différences de composition chimique pour les mêmes formules (tabl, 2).

L'utilisation de poudre de lait ne permettant pas de dépasser une teneur de 25 p. roo de matières azotées dans les aliments, nous avons choisi comme source d'azote complémentaire le concentrat de poisson (C.P.S.P. 9o) qui nous avait donné de très bons résultats lors d'un essai précédent (Theriez, Protais et MoleNAT, 1974). Cependant, comme nous avions également observé lors de ce même essai, une plus faible consommation de l'aliment contenant cette source de protéines, nous avons décidé de l'incorporer dans les 3 aliments " 20 ", " 25 " et " 30 " selon des taux très voisins ( 9 ou Io p. Ioo) pour éviter de trop grandes différences de consommation qui auraient rendu difficile l'étude de l'effet propre de la teneur en matières azotées sur les performances des agneaux.

Séparés de leur mère 6 à $\mathrm{i} 2$ heures après la naissance, tous les animaux ont été élevés en lots pendant leurs 3 premiers jours avec l'aliment " 25 ". A l'issue de cette phase initiale au cours de laquelle ils avaient appris à utiliser les tétines, les

(1) Dans la suite du texte nous désignerons les différents aliments d'allaitement par leur teneur théorique en matières azotées : 20,25 et 30 bien qu'aucun d'entre eux n'ait eu exactement la teneur prévue dans la formule. I,e dernier sera appelé aliment $s$. 
TABLEAC 2

Composition des aliments d'allaitement Composition of milk replacers

\begin{tabular}{|c|c|c|c|c|}
\hline $\begin{array}{l}\text { Constituant (p. 100) } \\
\quad(\text { Constituent })\end{array}$ & $\begin{array}{l}\text { Lait " } 20 " \\
\text { (Milk replacer } \\
\text { " } 20 \%)\end{array}$ & $\begin{array}{c}\text { Lait " } 25 " \\
\text { (Milk replacer } \\
\text { " } 25 》)\end{array}$ & $\begin{array}{l}\text { Lait " } 30 " \\
\text { (Milk replacer } \\
\text { " } 30 ")\end{array}$ & $\begin{array}{c}\text { Lait "S" } \\
\text { (Milk replacer } \\
\text { "S } \quad\end{array}$ \\
\hline 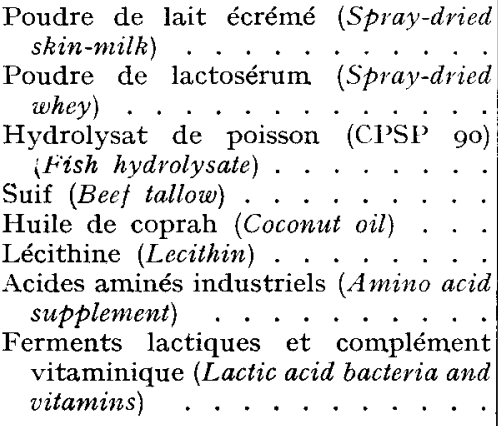 & $\begin{array}{l}20 \\
4 \mathrm{I}, 5 \\
9,0 \\
\mathrm{I} 6,5 \\
9,5 \\
\mathrm{I} \\
0\end{array}$ & $\begin{array}{l}4^{0} \\
22,5 \\
9,0 \\
16,0 \\
9,0 \\
1 \\
0\end{array}$ & $\begin{array}{c}63 \\
0 \\
\\
10,0 \\
15,0 \\
8,5 \\
1 \\
0\end{array}$ & $\begin{array}{c}7^{0,25} \\
0 \\
2,0 \\
15,0 \\
8,5 \\
1 \\
0,75 \\
2,5\end{array}$ \\
\hline $\begin{array}{l}\left.\text { Composition chimique (p. Ioo MS) }{ }^{1}\right) \\
\text { Chemical composition (p. Ioo DM) } \\
\text { Matières minérales }(\text { Ash). } \\
\text { Matières azotées (Crude protein) } \\
\text { Énergie }(\mathrm{kcal} / \mathrm{g}) \text { (Energy). } \\
\text { E. . . . }\end{array}$ & $\mid \begin{array}{r}5,5-6,1 \\
22,2-20,6 \\
5,56-5,30\end{array}$ & $\mid \begin{array}{r}5,6 \\
26,4-6,0 \\
5,66-2,3,3 \\
5,37\end{array}$ & $\mid \begin{array}{r}5,3 \\
31,8-3,6 \\
5,64-31,5 \\
5,45\end{array}$ & $\begin{array}{r}5.6 \\
28,8 \\
5,57\end{array}$ \\
\hline
\end{tabular}

(1) Pour chaque lait de remplacement nous avons reporté deux valeurs correspondant respectivement au premier et au second essai. (For each milk replacer two values are indicated cach corresponding to the first and the second trial, respectively.)

(2) Supplémentation en acides aminés (en p. Ioo de la MS) ILL méthionine o,25; L-isoleucine o,03; L- lysine $\mathrm{HCl}$ o,37; I-arginine o, Io. (A mino-acid supplementation $(\%$ of DM) DL methionine $0.25 ; L$-isoleucine 0.03 ; L-lysine $\mathrm{HCl} 0.37$ and L-arginine 0.10.$)$

agneaux ont été répartis entre les traitements en tenant compte de leur race et de leur poids à la naissance et à 3 jours.

Le lait de remplacement, reconstitué à raison de $200 \mathrm{~g}$ d'aliment par litre d'eau (Molenat et Theriez, 1974) et préparé à chaud $\left(45^{-50}{ }^{\circ} \mathrm{C}\right)$, était distribué à la température ambiante, soit dans des bouteilles munies d'une tétine et d'un tube plongeur (animaux en cases individuelles, essai I), soit dans des nourrisseurs équipés d'une tétine par animal (essai 2, en lots). Préparé chaque jour, il était laissé en permanence à la disposition des animaux.

Les agneaux nourris à volonté disposaient quotidiennement d'une quantité de lait suffisante pour permettre des refus voisins de Io p. Ioo du lait offert. Ceux qui subissaient une restriction recevaient une quantité de lait fixée à priori et qui diminuait linéairement, passant de 65 à $47 \mathrm{~g}$ de $\mathrm{MS} / \mathrm{kg}$ de poids métabolique entre 6 et $13 \mathrm{~kg}$ de poids vif. Les rations étaient ajustées deux fois par semaine. Le sevrage progressif, commencé à 35 jours, était terminé à 42 jours. 


\section{Phase de sevrage et d'engraissement}

A partir de 15 jours et jusqu'au poids moyen de $15 \mathrm{~kg}$ les agneaux disposaient à volonté, qu'ils soient sevrés ou non, de foin et d'un aliment concentré composé de maïs ( 72 p. I00), de tourteau de soja ( 25 p. I0o), de minéraux ( 2 p. IOo) et de chlorure d'ammonium ( $\mathrm{r}$ p. Ioo). La teneur en MAT de cet aliment, commun aux deux essais, s'élevait à I9,6 p. Ioo/MS.

Entre 15 et $20 \mathrm{~kg}$ de poids vif, les agneaux recevaient un mélange composé pour moitié de cet aliment concentré et pour moitié de l'aliment de finition. Celui-ci, offert seul à partir de $20 \mathrm{~kg}$ et jusqu'à l'abattage, était composé de maïs (73 p. Ioo pour l'essai I - 87 p. Ioo pour l'essai 2), de tourteau de soja (I5 p. Ioo dans les 2 essais), de tourteau de lin ( 8 p. Ioo, essai I seulement), de chlorure d'ammonium (I p. Ioo dans les 2 essais). Ces aliments contenaient respectivement I7,6 et I5, I p. Ioo de MAT/MS, ceci pour tenir compte de la nature du foin offert (dactyle lors du premier essai, luzerne lors du second). Au cours de la phase d'engraissement, les agneaux d'un même essai recevaient tous à volonté les mêmes aliments (foin et aliment concentré).

\section{Animaux}

Nous avons utilisé roo agneaux mâles Limousin ou Romanov. Limousin : 64 au cours du I er essai, soit i 6 animaux (dont 8 à volonté et 8 limités) par aliment et 36 au cours du $2^{\text {e }}$ essai, soit 3 lots de 4 agneaux par aliment. Ces Ioo animaux ont reçu les différents aliments d'allaitement pendant 6 semaines. Un groupe de 28 agneaux supplémentaires a été utilisé pour les mesures de digestibilité.

\section{Mesures}

Lors du I er essai, nous avons mesuré les coefficients de digestibilité et de rétention azotée des différents aliments d'allaitement (offerts sans compléments) et le coefficient de digestibilité seulement au cours du second. Les mesures ont eu lieu pendant les $2^{\mathrm{e}}$ et $3^{\mathrm{e}}$ semaines de vie (premier essai), ou pendant les $2^{\mathrm{e}}$ et $5^{\mathrm{e}}$ semaines (second essai) à l'aide d'agneaux munis de sac collecteur de fèces (Tissier, Bechet, Molenat, I975) et logés individuellement dans des cages à bilan. Lors de chaque mesure, nous avons utilisé 4 animaux pour chaque aliment.

Les fèces pesées chaque jour étaient séchées à $80^{\circ} \mathrm{C}$ pendant $72 \mathrm{~h}$. L'urine recueillie dans des flacons contenant $50 \mathrm{ml}$ d'acide chlorhydrique à 5 p. roo était pesée chaque jour et on en conservait le quart à - I $8^{\circ} \mathrm{C}$ en vue de $1^{\prime}$ analyse.

La teneur en énergie des laits et fèces a été déterminée à la bombe calorimétrique, la tencur en azote par la méthode de KJELDAHL et la teneur en cendres par incinération au four pendant $48 \mathrm{~h}$. Analyses et calculs ont été réalisés pour chaque animal séparément.

Les agneaux ont été pesés à la naissance, à 3 jours puis chaque semaine à jour et à heure fixes. Ils ont été abattus dès que leur poids vif atteignait $35 \mathrm{~kg}$ ou à l'âge de $\mathrm{I}_{40} \mathrm{j}$ au plus tard pour ceux qui n'avaient pas alors atteint ce poids.

Les quantités de lait consommées étaient mesurées chaque jour. Après sevrage, les rations offertes étaient préparées deux fois par semaine; les agneaux recevaient 
M. THERIEZ, P. PATUREAU-Mirand, G. MOLENAT

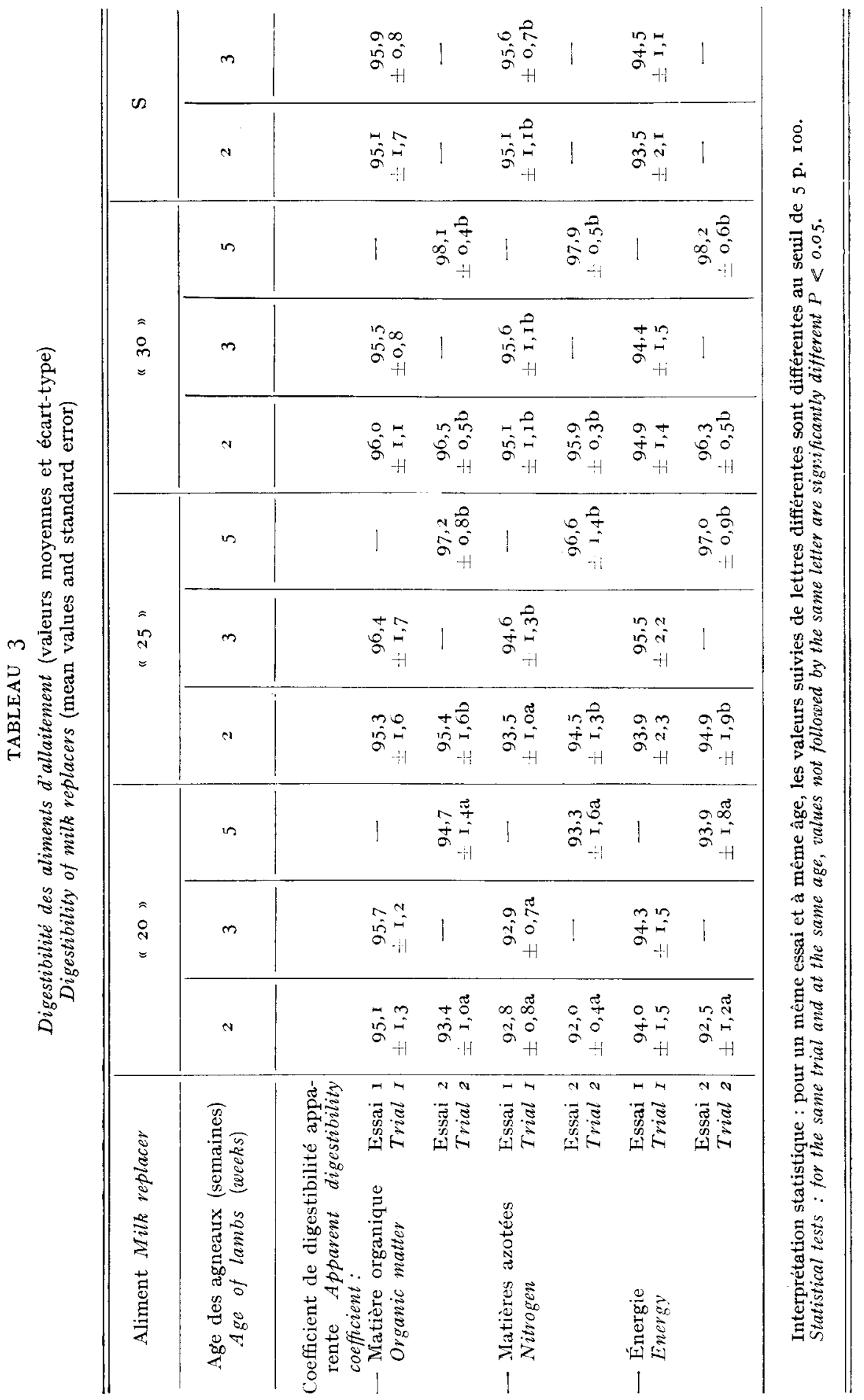


une nouvelle quantité d'aliment frais chaque jour. Les refus étaient pesés deux fois par semaine.

A l'abattage les mesures suivantes ont été réalisées : poids vif, poids de la carcasse froide, poids des dépôts adipeux mésentériques (toilette) et périrénal, épaisseur du gras de couverture au niveau de la r re vertèbre lombaire.

\section{Résultats}

\section{Digestibilité des différents aliments d'allaitement}

La digestibilité de la matière organique des différents aliments a varié entre. 95 et 98 p. Ioo. Dans les 2 essais, elle augmente avec la teneur en matières azotées. de l'aliment et l'âge des animaux (tabl. 3). Aucune des différences observées au.
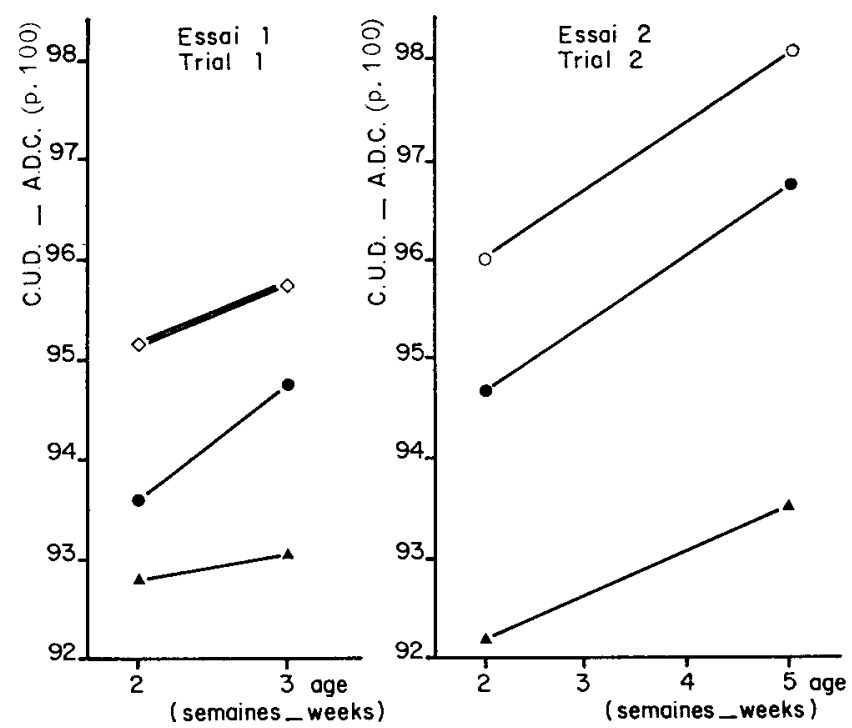

Fug. I. - Evolution du coefficient de digestibilité des matièves azotées avec l'âge des agneaux. Variation of nitrogen digestibility coefficient with the age of lambs.

Laits

Milk

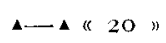

$\longrightarrow$ - 25 "

$0-0$ - 30

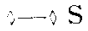

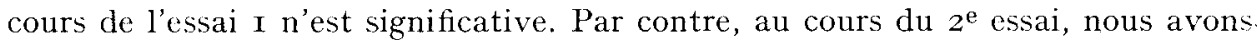
obtenu un effet significatif de la teneur en matières azotées (le lait " 20 " est significativement moins digestible que les 2 autres) et de l'âge (la digestibilité du lait " 30 " est significativement plus élevée à 5 semaines qu'à 2 semaines). La digestibilité de l'énergie, légèrement inférieure à celle de la matière organique varie. comme celle-ci.

Les différences de digestibilité entre aliments sont plus importantes avec les matières azotées : de 92,5 à 98,2 p. Ioo pour les extrêmes. La digestibilité de l'azote. augmente avec sa teneur : elle est significativement plus faible dans les aliments " 20 " et " 25 " par rapport aux aliments " 30 " et " $S$ " au cours du I"er essai et dans. 


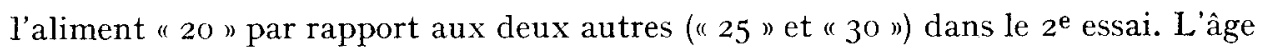
a également un effet sur la digestibilité des matières azotées, les valeurs obtenues à 3 ou 5 semaines sont plus élevées qu'à 2 semaines, les différences ne sont cependant significatives qu'entre 2 et 5 semaines (fig. I).

\section{Rétention azotée}

La quantité d'azote fixée par les agneaux ( $\mathrm{g} / \mathrm{j}$ ou $\mathrm{g} /$ Mcal ingérée) augmente avec la teneur en matières azotées des aliments (tabl. 4). Aucune des différences observées en $3^{\mathrm{e}}$ semaine n'est significative; par contre, en $2^{\mathrm{e}}$ semaine, les agneaux nourris avec les aliments " 30 " et " $S$ " fixent significativement plus d'azote que ceux qui reçoivent les aliments " 20 " et " 25 ". La quantité d'azote retenue par jour augmente aussi avec l'âge de la $2^{\mathrm{e}}$ à la $3^{\mathrm{e}}$ semaine, alors que la quantité fixée par Mcal ingérée diminue, mais aucune des différences n’est significative.

TABLEAU 4

Quantité d'azote fixée par les agneaux (valeur moyenne et écart-type) Quantity of nitrogen retained by the lambs (mean value and standard error) Essai I Ist trial

\begin{tabular}{|c|c|c|c|c|}
\hline $\begin{array}{c}\text { Aliment } \\
\text { Milk replacer }\end{array}$ & 20 & 25 & 30 & $\mathrm{~S}$ \\
\hline 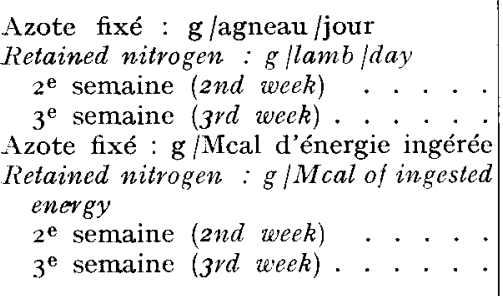 & $\begin{array}{l}4,49 \pm 0,2 a \\
4,3^{6} \pm 0,2\end{array}$ & $\begin{array}{l}5,05 \pm 0,5 \mathrm{a} \\
5,37 \pm 0, \mathrm{I}\end{array}$ & $\begin{array}{lll}7,4 & \ldots, 4 b \\
7,8 & \cdots & 0,8 \\
& & \\
& & \\
5,85 & \pm 0,8 b \\
5,32 & 1,0\end{array}$ & $\begin{array}{l}6,25 \pm 0,6 b \\
5,38 \pm 0,7\end{array}$ \\
\hline
\end{tabular}

Interprétation statistique : voir tableau 3.

Statistical tests for differences between treatments are prescuted in table 3 .

Le coefficient de rétention azotée décroît lorsque le taux protéique de l'aliment augmente de 20 à 25 et $30 \mathrm{p}$. Ioo, passant respectivement de 76,0 à 72,0 et 67,6 p. Ioo à 2 semaines et de 73,4 à 76,4 et 63,6 p. Ioo à 3 semaines. Les valeurs observées avec l'aliment " $\mathrm{S}$ » $(76,0$ et 67,5 p. Ioo à 2 et 3 semaines) sont significativement supérieures à celles obtenues avec l'aliment " 30 ). Il diminue aussi avec l'âge, surtout chez les agneaux qui reçoivent les aliments ayant les teneurs en matières azotées les plus élevées (aliments " 30 " et " $\mathrm{S}$ "). 


\section{Quantités d'aliments ingérées}

Au cours du premier essai, les quantités de lait de remplacement (ou les quantités de matière sèche) ingérées entre 9 et 35 jours sont les mêmes pour l'ensemble des agneaux nourris à volonté ( 481 soit $7,7 \mathrm{~kg}$ de matière sèche) quelle que soit la teneur en MA de l'aliment. Il en est de même pour les agneaux restreints $(4 \mathrm{I}, 21$ soit $6,6 \mathrm{~kg}$ de MS) qui ont reçu I $_{5}$ p. Ioo de MS de moins que leurs homologues nourris à volonté (tabl. 5).

Par contre, au cours de l'essai 2, les agneaux qui recevaient le lait le plus riche en MA (lait " 30 ") ont consommé plus de matière sèche $(9,7 \mathrm{~kg}$ contre 8,4 et $8,2 \mathrm{~kg}$ pour les lots " 20 " et " 25 »).

Après le sevrage, les agneaux ont ingéré d'autant plus d'aliment concentré qu'ils avaient consommé moins de lait de remplacement : de 54,5 à $63 \mathrm{~kg}$ par agneau selon les lots. La nature du foin offert a modifié le rapport fourrage/aliment concentré. Les agneaux qui recevaient du foin de dactyle (essai $\mathbf{r}$ ) ont consommé une quantité de fourrage deux fois plus faible que ceux qui disposaient de foin de luzerne (essai 2).

\section{Vitesse de croissance des agneaux}

Bien que la quantité totale de matières azotées ingérée ait varié dans des proportions importantes (de I,5 à 3,o kg entre les lots extrêmes), il n'existe aucune liaison significative entre le gain de poids vif au cours de la phase lactée (o à 35 j) et la quantité totale de matières azotées ingérées.

Par contre le gain de poids ( $Y$ exprimé en $\mathrm{kg}$ ) au cours de cette période est lié de manière hautement significative à la quantité totale de matière sèche ingérée entre 9 et $35 \mathrm{j}$ ( $\mathrm{X}$ exprimé en $\mathrm{kg}$ ). Les équations obtenues au cours du $\mathrm{I}^{\text {er }}$ essai sont les suivants :

$\mathrm{Y}=0,827 \mathrm{X}+2,26 \quad r=+0,903, \mathrm{P}<0,0 \mathrm{I}$ pour $3 \mathrm{I}$ agneaux nourris à volonté et $\mathrm{Y}=0,869 \mathrm{X}+2$, Io $r=+0,59 \mathrm{I}, \mathrm{P}<0$, oI pour 30 agneaux restreints.

De telles équations n'auraient pas de signification dans le $2^{\mathrm{e}}$ essai puisqu'à une augmentation de la teneur en matières azotées est alors associée une augmentation de la quantité de matière sèche ingérée (cas des lots " 30 " par rapport aux lots " 20 " et " 25 "). Par contre, c'est dans ce cas que nous avons pu obtenir la seule différence significative de vitesse de croissance entre lots sans que l'origine de cette différence puisse être attribuée à la teneur en matières azotées ou au niveau moyen de consommation.

Après sevrage, quelle que soit la teneur en matières azotées du lait de remplacement et le niveau d'apport, tous les agneaux ont eu des croissances très rapides (de 320 à $400 \mathrm{~g} / \mathrm{j}$ ) et les premiers agneaux ont été abattus dès l'âge de $80 \mathrm{j}$. Pour des poids vifs moyens voisins, l'âge d'abattage des différents lots est compris entre ro6 et I $I_{4}$ j pour les agneaux restreints et, pour ceux qui avaient été nourris à volonté, I03 et I 07 jours lors de l'essai I, 96 à I 07 jours lors de l'essai 2 (aucune différence significative).

Les vitesses de croissance élevées ont permis d'obtenir des indices de consommation très satisfaisants, de I, 06 à $I, 30 \mathrm{~kg}$ de MS $/ \mathrm{kg}$ de gain de poids vif au cours de la phase lactée (différences non significatives, ni entre aliments ni entre essais). $\mathrm{Au}$ cours de la phase d'engraissement les indices de consommation sont également 


\begin{tabular}{|c|c|c|c|c|c|c|}
\hline \multirow{3}{*}{\multicolumn{2}{|c|}{ 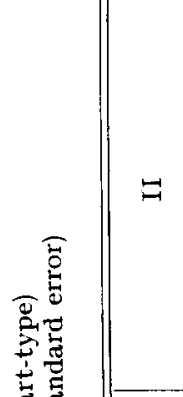 }} & \multirow{3}{*}{ 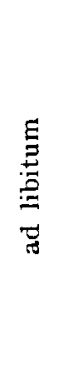 } & $\dot{m}$ & 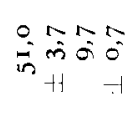 & 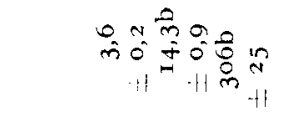 & $\begin{array}{ll}0 & 0 \\
0 & 0 \\
-1 & 1\end{array}$ \\
\hline & & & $\stackrel{\sim n}{\sim}$ & 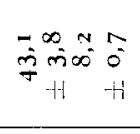 & 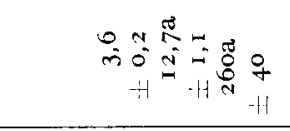 & $\begin{array}{l}=0 \\
=0\end{array}$ \\
\hline & & & $\stackrel{\curvearrowright}{\circ}$ & 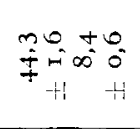 & 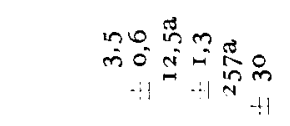 & $\begin{array}{l}=5 \\
=7\end{array}$ \\
\hline 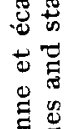 & & & $n$ & $\ln _{+1}^{\infty} \frac{1000}{4}=$ & 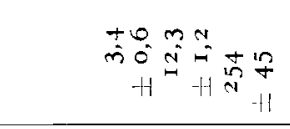 & $\stackrel{7}{=}=$ \\
\hline 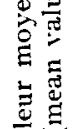 & & $\underset{\Xi}{\Xi}$ & $\stackrel{\circ}{m}$ & $\begin{array}{l}\infty \\
0 \\
0\end{array} 0=$ & 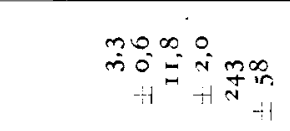 & $\stackrel{9}{=}$ \\
\hline 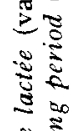 & & $\overrightarrow{7}$ & $\stackrel{n}{i}$ & 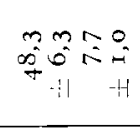 & 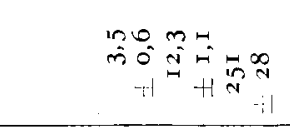 & $\stackrel{\infty}{=}$ \\
\hline 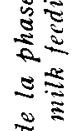 & -1 & & $\stackrel{i}{\mathrm{~N}}$ & $\begin{array}{r}0002= \\
005= \\
11=\end{array}$ & 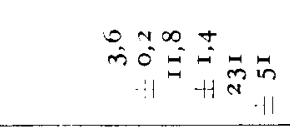 & $\cong$ \\
\hline 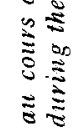 & & & in & 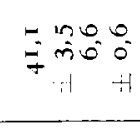 & 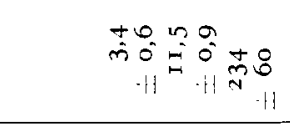 & $=$ \\
\hline 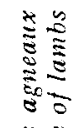 & & 芯 & $\stackrel{\circ}{m}$ & 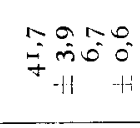 & $\begin{array}{l}n=0 \\
m 0=0 \\
-11\end{array}$ & $\stackrel{8}{=}$ \\
\hline 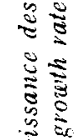 & & 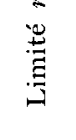 & $\ddot{r}$ & 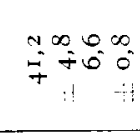 & 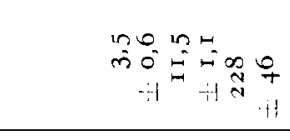 & 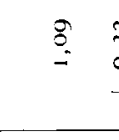 \\
\hline 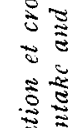 & & & $\stackrel{i}{ }$ & 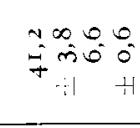 & 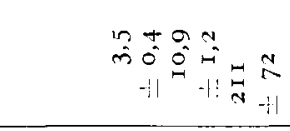 & $\stackrel{8}{=}$ \\
\hline 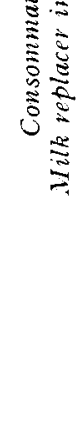 & 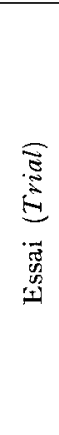 & 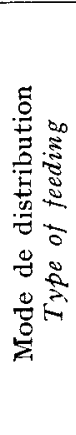 & 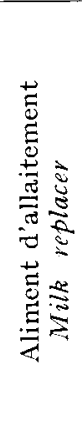 & 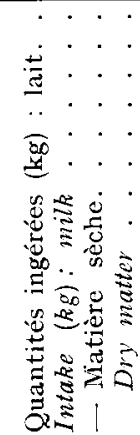 & 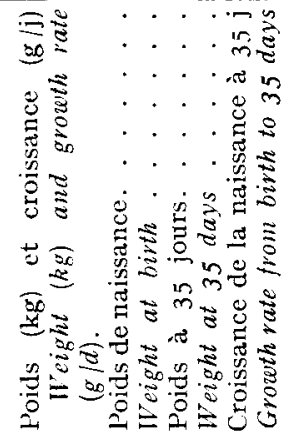 & 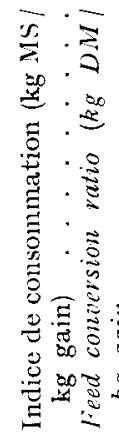 \\
\hline
\end{tabular}




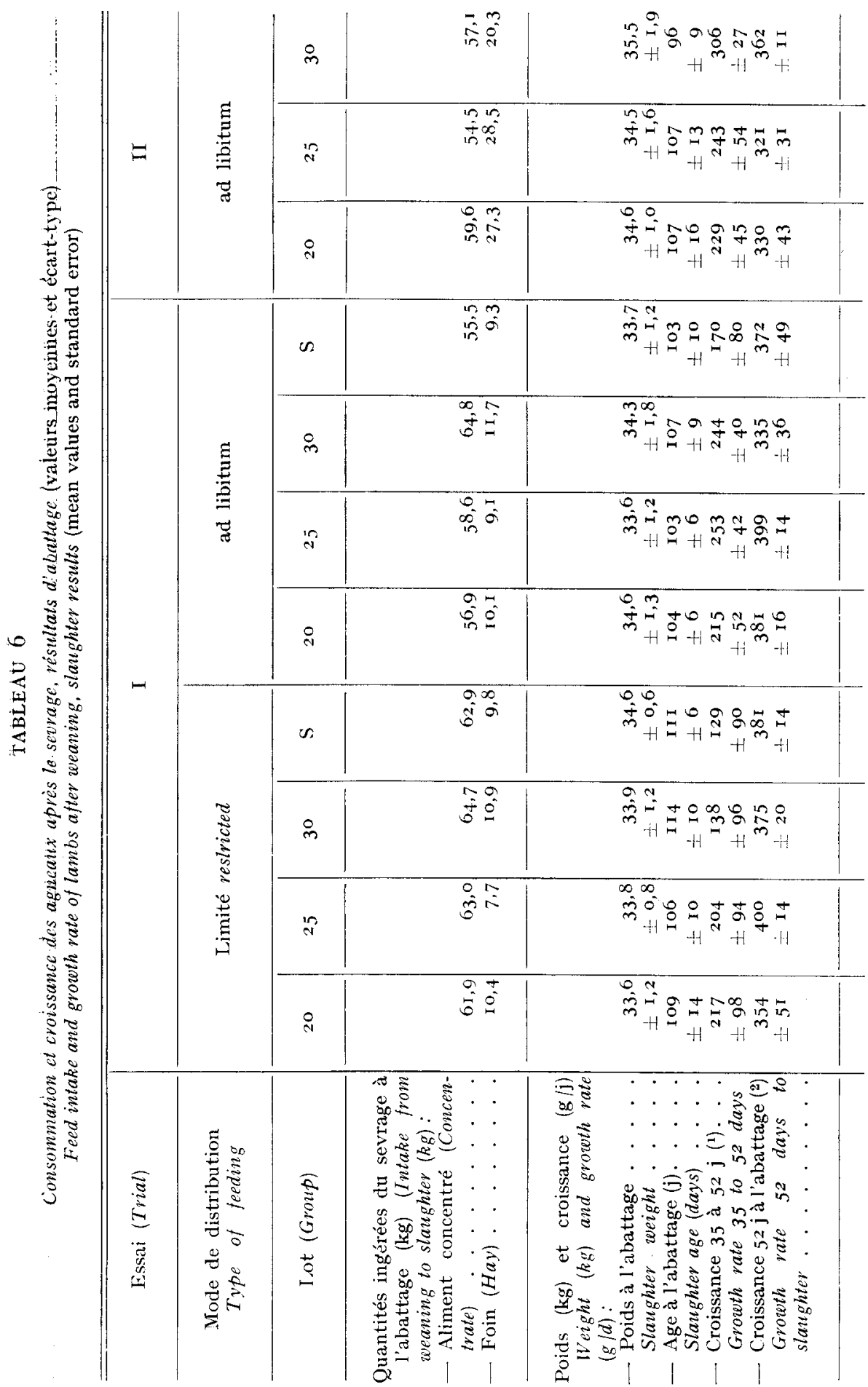



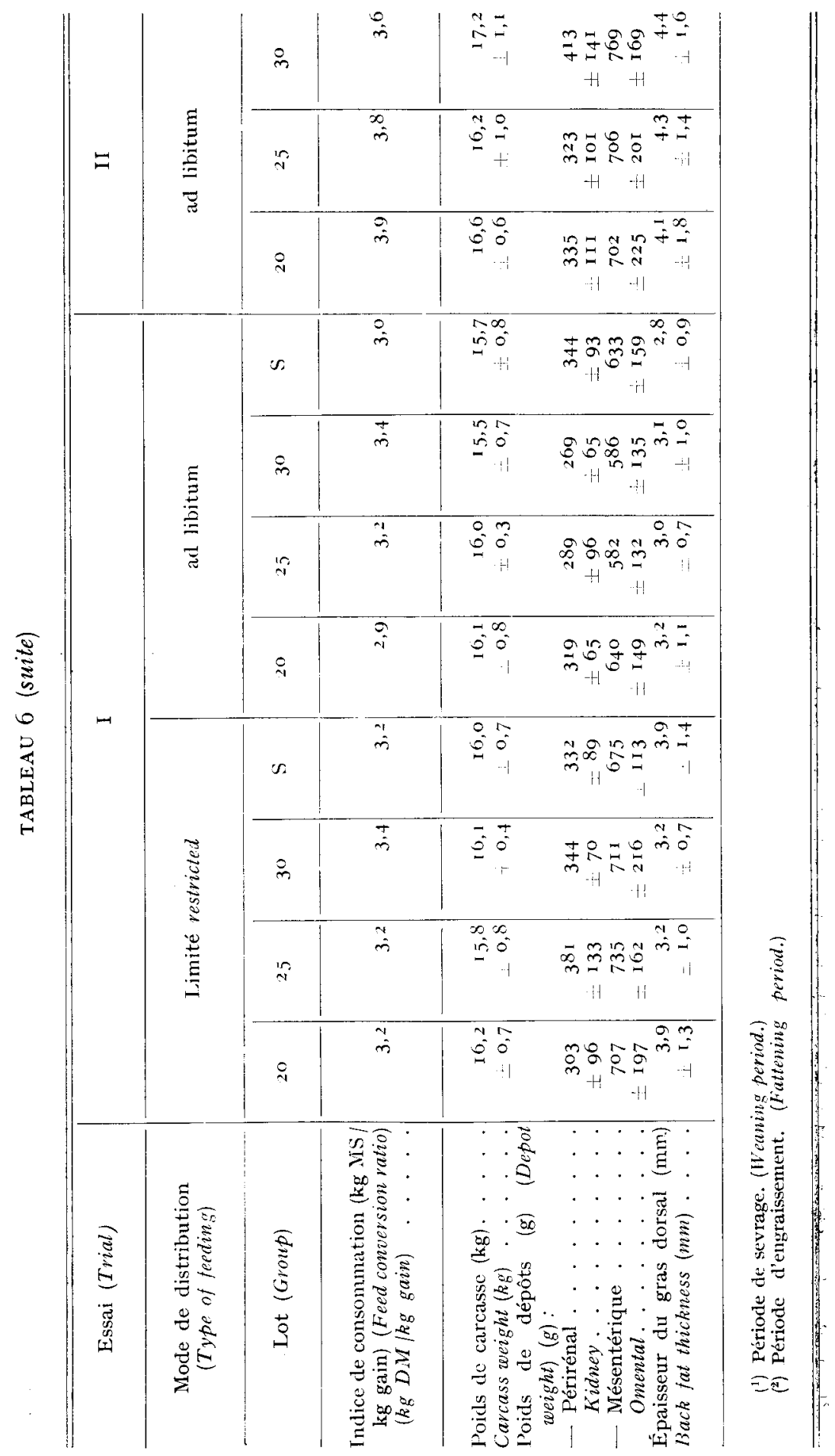
très bons : 3,2 et $3,8 \mathrm{~kg}$ de MS $/ \mathrm{kg}$ de gain de poids vif (respectivement pour l'essai I avec I5 p. Ioo de fourrage dans le régime et pour l'essai 2 avec $30 \mathrm{p}$. Ioo de foin dans le régime).

\section{Résultats d'abattage}

Les agneaux pesaient de 33,6 à $34,6 \mathrm{~kg}$ à l'abattage à l'issue du $\mathrm{I}^{\mathrm{er}}$ essai et de 34,5 à $35,5 \mathrm{~kg}$ à l'issue du second. Plus lourds, ces agneaux ont donné des carcasses plus lourdes et plus grasses (tabl. 7).

La composition de l'aliment d'allaitement n'a modifié ni le rendement à l'abattage, ni l'état d'engraissement estimé par le poids des dépôts adipeux périrénaux ou mésentériques et par l'épaisseur du gras de couverture au niveau de la première vertèbre lombaire.

Par contre, bien que les différences ne soient pas significatives, la limitation du lait au cours de la phase lactée dans l'essai I a entraîné une augmentation de l'état d'engraissement mesuré par l'importance des dépôts internes, et par l'épaisseur du gras dorsal.

\section{Discussion}

Comme dans un essai précédent (Theriez, Protais et Molenat, I974), nous avons constaté une augmentation de la digestibilité de la matière organique et de l'azote des laits de remplacement avec l'âge des agneaux, effet conforme à celui observé sur le veau par Frantzen, Toullec et Mathieu (I97I) mais que divers autres auteurs (WALKer et Faichney, I964; Chiou et Jordan, I973a) n'ont pu mettre en évidence sur l'agneau. Inversement, NorTon et WALKER (I97I) ont même obtenu une diminution significative du CUD de l'azote entre la $2^{\mathbf{e}}$ et la $7^{\mathrm{e}}$ semaine d'âge mais seulement avec un aliment d'allaitement contenant 6 p. Ioo de protéines alors qu'ils n'observaient aucun effet de l'âge sur la digestibilité d'un régime contenant $28,5 \mathrm{p}$. Ioo de matières azotées.

L'augmentation de la digestibilité de l'aliment pourrait être due dans notre cas à la nature des matières azotées utilisées. En effet, nous avons incorporé 9 à Io p. Ioo de concentré protéique de poisson dans nos aliments ainsi que o à $40 \mathrm{p}$. Ioo de poudre de lactosérum. Or ces deux aliments qui représentaient de 15 à 67 p. roo des matières azotées, sont moins digestibles que la poudre de lait tant pour l'agneau (Theriez, Protais et Molenat, I974) que pour le veau (Toullec et al., i973) en partie parce qu'elles ne coagulent pas dans la caillette. L'influence de l'absence de coagulation dans la caillette sur la digestibilité des matières azotées diminuant avec l'âge de l'animal (Frantzen, Toullec et Mathieu, i97I) on aurait donc là une origine possible de l'augmentation du CUD. Ce phénomène n'est cependant pas seul en cause car l'augmentation du CUD est sensiblement identique, entre deux et cinq semaines d'âge, pour tous les aliments quelle que soit leur composition donc la proportion des trois sources d'azote utilisées. Par ailleurs les valeurs élevées tant du CLD que de la rétention azotée dès l'âge de deux semaines permettent d'éliminer l'hypothèse d'une mauvaise qualité de la poudre de lait.

De même l'augmentation de la digestibilité des matières azotées avec l'accroissement de leur teneur n'est pas due seulement à la réduction de l'importance relative des sources azotées de remplacement. En effet, d'une part, la proportion de concentré de poisson reste presque constante dans les trois aliments " 20,25 et 30 " dans lesquels nous avons augmenté la teneur en azote par remplacement 
de la poudre de lactosérum par du lait écrémé en poudre et, d'autre part, les aliments " 30 et $S$ ", qui ne contiennent pas de poudre de lactosérum, ont la même digestibilité alors que la proportion de concentré de poisson y est de ro et $2 \mathrm{p}$. Ioo respectivement. L'augmentation du CUD correspond donc bien à un effet propre de la teneur en matières azotées de l'aliment. Cette augmentation de la digestibilité des matières azotées lorsque le taux protéique augmente reflète la forte digestibilité réelle des protéines alimentaires. L'azote fécal $(0,23 \mathrm{~g}$ pour Ioo g de MS ingérée en $2^{\mathrm{e}}$ et $3^{\mathrm{e}}$ semaine) est alors principalement constitué d'azote métabolique fécal dont l'excrétion varie peu en fonction de la quantité d'azote ingéré $(0,20 \mathrm{~g}$ pour roo g de MS ingérée selon Black, Pearce et Tribe, r973).

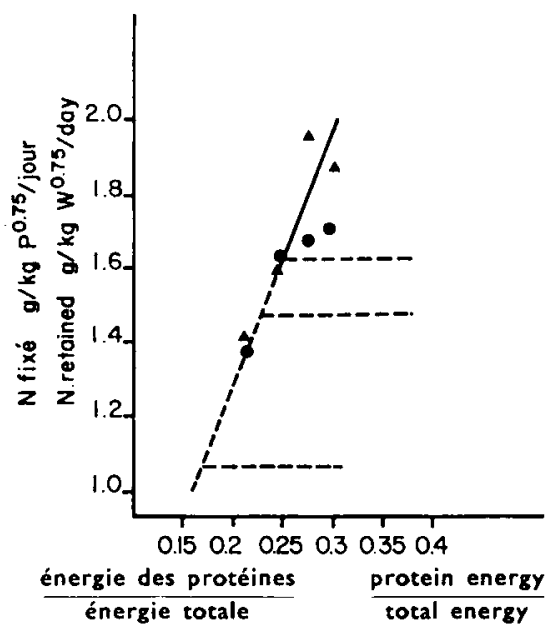

Iirc. 2. - Quantité d'azote fixé par $k g$ de poids métabolique et par jour.

Sur la courbe en traits pointillés empruntée à Black, Pearce et Tribe et que nous avons extrapolée (trait plein), nous avons reporté les valeurs expérimentales obtenues à 2 semaines (4) ou $\dot{a} 3$ semaines (•).

Quantity of retained nitrogen per $k g$ of metabolic weight and per day.

On the cure (dotted line) of Black. Pearce and Tyibe (1973) that we have extended (full linc), experimental values obtaine'd at two (4) or three weeks (1) of age, are reported.

Un tel effet a été également observé par WaLkER et FaIchNeY (I964), WaLKER et Nortox (I97I), Walker et CoOK (I967) sur l'agneau et par RAVEN (I972) sur le veau.

Le coefficient de rétention azotée et la quantité d'azote fixée par mégacalorie d'énergie brute ingérée varient en sens inverse du CUD. Ils diminuent lorsque l'âge des animaux et le taux azoté de l'aliment augmentent car les pertes d'azote urinaire, correspondant au catabolisme des acides aminés lors de leur utilisation à des fins énergétiques, augmentent plus rapidement que la quantité de matières azotées ingérée. L'effet de l'âge sur la fixation d'azote a déjà été signalé à de nombreuses reprises (ChIOU et JORDAN, I973 $a$ et $c$; NorTon et WALKER, I97I; WaLKER et FAICHNEY, I964) mais les valeurs absolues indiquées étaient beaucoup plus faibles par suite essentiellement d'apports de matières azotées plus réduits. Seuls les agneaux élevés par BLACK, PEARCE et TRIBE (I973) et gagnant 270 à $300 \mathrm{~g} / \mathrm{j}$, ont retenu des quantités d'azote voisines de celles que nous avons observées aussi bien dans le présent travail $(5,5$ à $7,5 \mathrm{~g}$ d'azote par agneau et par $\mathrm{j}$ ) que dans une expérience antérieure (Theriez, Protais et Molenat, i974). Ces 
quantités, qui varient de $I, 8$ à 2,o g d'azote par $\mathrm{kg}$ de poids métabolique et par jour pour des agneaux pesant $6 \mathrm{~kg}$ de poids vif, semblent correspondre à un maximum comme cela apparaît sur la figure 2 construite à partir d'une courbe de BLACK, PFARCE et TRIBE (I 973) sur laquelle nous avons reporté nos résultats.

L'examen de la figure 2, permet de comprendre pourquoi, malgré un coefficient de rétention plus élevé, les agneaux qui recevaient l'aliment supplémenté en acides aminés n'ont pas fixé plus d'azote que ceux du lot " 30 ». Compte tenu de l'apport énergétique, le maximum de rétention d'azote était déjà atteint pour des animaux de ce poids et, à la différence de WALKER (I975) qui a supplémenté en méthionine un " lait " contenant seulement 12 p. Ioo de matières azotées, l'apport des quatre acides aminés industriels n'a pas pu avoir d'effet sur la quantité d'azote fixée.

Si l'augmentation de la teneur en matières azotées a permis d'améliorer significativement le bilan azoté des agneaux, nous n'avons, à la différence de certains auteurs dont Chiou et Jordan (I973c), Walker et Faichney (I964) observé aucun effet sur la vitesse de croissance. Ce résultat provient du fait que, dans leurs expériences, le niveau azoté variait de $I_{5}$ à 30 , voire de 6 à 28 p. Ioo (Norton et WALKER, I97I) et que le niveau d'apport de matière sèche, donc les croissances, étaient limitées. Par contre, si l'on reprend les résultats de BLAck, PeARCE et Tribe (1973) dont les agneaux recevaient une quantité d'énergie correspondant à environ 3 fois l'entretien, on constate qu'avec un aliment ayant une teneur de I5 p. Ioo de matières azotées, les vitesses de croissance sont significativement inférieures à celles des autres lots mais que les écarts observés entre les lots ne sont plus significatifs dès que la teneur des matières azotées de leur aliment atteint ou dépasse $20 \mathrm{p}$. roo (ce résultat étant valable pour des poids vifs moyens variant de 7,8 à $12,6 \mathrm{~kg}$ ).

Pour des niveaux d'apports énergétiques supérieurs à I,75 fois l'entretien, le besoin en protéines rapporté à l'énergie pouvant être considéré, selon WALKER et JAGUSCH (I969), comme constant et voisin de I 2 g par M Joule d'énergie nette, l'agneau qui reçoit des régimes pauvres en matières azotées (I5 p. Ioo ou moins) voit sa croissance limitée par l'apport d'azote. Le gain de poids est alors plus riche en lipides (Jagusch, Norton et Walker, I970; Walker et Norton, I97 i Chiou et JORDAN, I973b) et la croissance de la laine réduite (WALKER et NORTON, I97I). Au contraire, pour les aliments riches en matières azotées ( 25 ou $30 \mathrm{p}$. Ioo et plus) la quantité d'azote fixée par jour atteint un maximum et dans ce cas l'énergie peut devenir facteur limitant. Ainsi peuvent s'expliquer les résultats de BLACK, PEARCE et Tribe (I973) de même que nos observations présentes puisque nous avons obtenu une corrélation hautement significative entre la quantité de matière sèche ingérée et la vitesse de croissance. La modification de la composition corporelle résultant de l'excès de matières azotées par rapport à l'énergie demeure toutefois assez faible puisque CHIOU et JoRDAN (1973 b) n'ont obtenu que 2 p. Ioo d'écart dans la teneur en protéines du corps d'agneaux qui avaient reçu des laits contenant I 5 ou $30 \mathrm{p}$. Ioo de matières azotées. Il n'est donc pas étonnant que nous n'ayons pas observé d'effet du niveau azoté des aliments d'allaitement sur l'état d'engraissement à l'abattage vers i Io $j$, soit plus de $70 \mathrm{j}$ après le sevrage.

Pour augmenter la vitesse de croissance de l'agneau, il serait donc nécessaire non pas d'accroître la teneur en protéines des aliments au delà de 25 p. Ioo mais, soit de les rendre plus appétibles (cas du lait 30 dans l'essai 2 dont l'appétibilité supérieure a une origine inconnue), soit d'augmenter l'apport quotidien d'énergie. L'augmentation de la concentration énergétique ne semble guère possible, tout au moins avec des aliments contenant des matières grasses naturelles, car si dans cer- 
tains cas les résultats obtenus sont positifs (WELCH et VAN DER NoOT, Ig63; BRISSON et LEMAY, I968) des effets nuls, voire négatifs, ont également été observés (Molenat et Theriez, I972). De même l'augmentation de la teneur en matière sèche de l'aliment d'allaitement ne permet pas d'accroître la quantité de matière sèche donc d'énergie ingérée par jour (LARGE, I965; Molenat et Theriez, I974).

L'utilisation de deux aliments différents, l'un contenant $30 \mathrm{p}$. Ioo de matières azotées pour les 3 premières semaines, l'autre plus pauvre (25 ou $20 \mathrm{p}$. I OO) pour la fin de la période lactée serait la meilleure façon d'assurer à l'agneau la fixation maximum de protéines au cours de ses premières semaines de vie. Mais cette solution n'est pas réaliste car elle se heurte à des difficultés de réalisation pratique, tout au moins pour les éleveurs qui n'utilisent l'aliment artificiel que sur un petit nombre d'agneaux. C'est pourquoi la teneur à 25 p. Ioo semble correspondre le mieux aux besoins de l'animal, de préférence à des teneurs plus faibles de l'ordre de 20 p. roo. Celles-ci n'ont pas d'effet sensible sur la croissance de l'animal riais elles nécessitent l'utilisation de sources de matières azotées bien équilibrées cn acides aminés et de bonne qualité.

Accepté pour publication en mars 1977 .

\section{Summary}

\section{Artificial rearing of lambs. VI. - Comparison of milk replacers with different crude protein contents}

Four milk replacers containing 20,25 or 30 per cent protein or 29 per cent protein +0.25 per cent DL-methionine, 0.37 per cent L-lysine, 0.03 per cent $\mathrm{I}$,-isoleucine and 0.10 per cent $\mathrm{L}$.-arginine were compared during 2 successive trials (Table 2). 1)igestibility and nitrogen retention coefficients of the feeds were measured. The diets were offered for 6 weeks to roo lambs $(64$ in trial 1 and $3^{6}$ in trial 2). During the second trial, we compared only 3 milk replacers, " 20,25 and $30 \%$.

The 64 lambs of trial 1 were housed in individual cages, each diet was given to 16 animals among which 8 were fed ad libitum and 8 restricted. The 36 lambs of trial 2 were reared in groups (3 groups of 4 lambs per diet) and fed ad libitum. After weaning the animals were distributed into groups according to the initial treatment and fattened until $3.5 \mathrm{~kg}$ live weight with hay and concentrate feed.

Digestibility of organic matter, energy and protein increased with the crude protein content of the diet and with the age of the animals (Table 3, fig. 1). The amount of apparently digestible nitrogen retained decreased with the age of the animals and with the dictary crude protein level except for the amino acid supplemented diet whose nitrogen retention coefficient exceeded that of diet " 30 " (Table 4). The amount of nitrogen retained per day increased with the dietary protein level and with the age. The highest values ranged about $7.5 \mathrm{~g}$ (Table 5 ).

The dietary crude protein level did not affect the animals' growth rate which was signiticantly related with the dry matter intake and not with the protein intake (Table 6). After weaning, the growth rates of the lambs were high and we did not observe any effect of the crude protein level of the milk replacer either on post-weaning growth rate or on carcass fatness (Table 7 ).

A protein level of 25 per cent in the milk replacer seems to be the best adapted to the requirements of young growing lambs. It leads to the same weight gains as higher levels and does not require an expensive supplementation with commercial amino acids which might be necessary with lower levels, according to the nature of the protein source.

\section{Références bibliographiques}

Black J. L., Pearce G. R., Tribe D. E., 1973. Protein requirements of growing lambs. $B r . J$. Nutr., 30, 45-60.

Brisson G. J., Lemay J. I'., I968. Comparison between rations of different protein: energy ratio for lambs weaned at three or at fifteen days of age, Can. J. Anim. Sci., 48, 307-313. 
Chiou W. S., Jordan R. M., 1973. Ewe milk replacer diets for young lambs.

$a$ : I. Effects of age of lamb and dietary fat on digestibility of the diet, nitrogen retention and plasma constituents. J. Anim. Sci., 36, 597-606.

$b$ : III. Effect of age of lamb and dietary protein and fat levels on the body composition of young lambs. J. Anim. Sci., 36, 607 .

$c$ : IV. Protein and energy requirements of young lambs. J. Anim. Sci, 37, $581-587$

Frantzen J. F., Toullec R., Mathieu C. M., I971. Influence de la coagulation sur l'utilisation digestive des matières azotées du lait. Xe Congrìs International de Zootechnie, Versailles, I 7-23 juillet.

Jagush K. T., Norton B. W., Walker D. M., i97o. Body composition studies with the milkfed lamb. I. The effect of age of the lambs and the protein content of the diet on the chemical composition of the body and its organs. J. Agr. Sci., 75, 279-285.

I.ARGE R. V., I 965 . The effect of concentration of milk substitute on performance of artificially reared lambs. Anim. Prod., 7, 325-332.

Molenat G., Theriez M., I972. L'allaitement artificiel des agneaux. II. Influence de la teneur en matières grasses du lait de remplacement. Ann. Zootech., 21, 385-399.

Molenat G., Theriez M., 1974. L'allaitement artificiel de l'agneau. V. Comparaison de différentes concentrations du lait de remplacement. Ann. Zootech., 23, 491-502.

Norton B. W., Walker D. Mi., 197I. Nitrogen balance studies with the milk fed lambs.7. Effect of age of the lamb. Br. J. Nutr., 26, I-6.

Patureau-Mirand P., Theriez M., Prugnaud I., Pion R., 1977. Influence du taux protéique et de la composition en acides aminés de l'aliment d'allaitement sur l'a mino acidémie de l'agneau préruminant. Ann. Zootech. 26, 3I 5-328.

RAvEN A. M., 1972. Nutritional effects of including different levels and sources of protein in milk for calves. J. Sci. Fd. Agric., 23, 517-526.

Theriez M., Protais M., Molenat G., ig74. L'allaitement artificiel desagneaux. IV. Comparaison de différentes sources de matières azotées en remplacement de la poudre de lait. Ann. Zootech., 23, 325-34I.

Tissier Mi., Bechet G., Molenat G., 1975. Appareils de collecte totale des fèces pour agneaux à l'allaitement ou à l'engrais et pour brebis. Ann. Zootech., 24, 595-602.

Toullec R., Patureau-Mirand P., Paruelle I. L., Guilhermet R., I973. Utilisation des protéines par le veau préruminant à l'engrais. L'alim. ct la vie, 61, 57-92.

WALKER D. M., 1975. Methionine supplementation of milk protein for preruminant lambs. II. Effect on wool growth, live weight gain and body composition. Aust. J. Agric. Res., 26, $68 \mathrm{I}-688$.

Walker D. M., Cook I. Y., 1967. Nitrogen balance studies with the milk fed lamb. 4. Effect of different nitrogen and sulphur intakes on live weight gain and wool and on nitrogen and sulphur balances. Br. J. Nutr., 21, $237-256$.

Walker D. M., Faichney G. J., r964. Nitrogen balances studies with the milk fed lamb. 3. Effect of different nitrogen intakes on growth and nitrogen balances. Br. J. Nutr., 18, 29.5306.

Walker D. M., Jagusch K. T., I 969 . Utilization of the metabolizable cnergy of cow's milk by the lamb. Europ. Ass. Anim. Prod., 12, I87-192.

WALKER D. M., KIRK R. D., 1975. Methionine supplementation of milk protein for preruminant lamb. I. Effect of protein concentration and source of carbohydrate on nitrogen balance. Aust. J. Agri. Res., 26, 673-679.

Walker D. M., Norton B. W., 1971. Nitrogen balance studies with the milk fed lamb. 9. Energy and protein requirements for maintenance, live-weight gain and wool growth. $B r$. f. Nitv., 26, I 5-29.

Welch J. G., VAN der NoOT G. N., 1903. Effect of feeding milk replacers with varying amounts of fat for hothouse lamb production. J. Anim. Sci., 22, 15.5-158. 